\title{
Public health agendas addressing violence against rural women - an analysis of local level health services in the State of Rio Grande do Sul, Brazil
}

Marta Cocco da Costa ${ }^{1}$

Marta Julia Marques Lopes ${ }^{2}$

Joannie dos Santos Fachinelli Soares ${ }^{2}$

${ }^{1}$ Departamento de Ciências da Saúde, Universidade Federal de Santa Maria. Av. Independência 3751, Vista Alegre. 98300-000 Palmeira das Missões RS Brasil. marta.c.c@ufsm.br ${ }^{2}$ Departamento de Assistência e Orientação Profissional, Escola de Enfermagem, Universidade Federal do Rio Grande do Sul.

\begin{abstract}
This study analyses health managers' perceptions of local public health agendas addressing violence against rural women in municipalities in the southern part of the State Rio Grande do Sul in Brazil. It consists of an exploratory descriptive study utilizing a qualitative approach. $\mathrm{Mu}$ nicipal health managers responsible for planning actions directed at women's health and primary health care were interviewed. The analysis sought to explore elements of programmatic vulnerability related to violence in the interviewees' narratives based on the following dimensions of programmatic vulnerability: expression of commitment, transformation of commitment into action, and planning and coordination. It was found that local health agendas directed at violence against rural women do not exist. Health managers are therefore faced with the challenge of defining lines of action in accordance with the guidelines and principles of the SUS. The repercussions of this situation are expressed in fragile comprehensive services for these women and programmatic vulnerability.
\end{abstract}

Key words Violence against women, Health of the rural population, Vulnerability, Health manager 


\section{Introduction}

Violence seriously affects health since, apart from physical and emotional harm and risk of death, it also negatively affects the quality of life of individuals and the community. Violence therefore poses new problems for preventative and curative medical care because addressing this problem requires changes to health care services and the adoption of an interdisciplinary and intersectoral approach ${ }^{1}$.

With regard to violence against women, the problem frequently remains invisible in healthcare due to technological obstacles. Under the hegemony of the biomedical model violence is not considered a legitimate public health issue which means that many health professionals experience difficulties in dealing with violence ${ }^{2}$.

With respect to violence in the rural context, the few studies that address this issue point to ignorance within the profession regarding women's general health status and the specific and unique characteristics of the social, family and work situation of women. As a result, violence against rural women is not considered a target of public health interventions which requires specific effective care.

The rural context in Brazil, particularly in the case of women, is permeated by submission and resistance generated and manifested through class, gender, ethnic and land conflicts etc., where violence is often used as a means of solving disputes. Agrarian conflicts emerge within this socioeconomic context led by different social agents in an attempt to minimise the impacts of changes caused by agribusiness and an economic model based on the modernisation of agriculture, which leads to an increase in social exclusion, migration from rural areas to cities and impoverishment of farmers ${ }^{3}$. Theses cenarios lead to vulnerability among certain social groups and family environments.

Based on the above elements, this study recognises the existence of programmatic vulnerability (inexistence of programmes at local level) in health which potentially and particularly affects women in rural areas subjected to violence. In general terms, programmatic vulnerability comprises an effort to produce and disseminate knowledge, and presents, for analytical purposes, a scheme, referring to individual, social and programmatic service plans, emphasising that, in fact, the different dimensions of vulnerability form an indivisible whole. Based upon studies carried out by Ayres et al. ${ }^{4}$, the present article analyses the programmatic dimension of vulnerability, since this dimension seeks to evaluate how, in given social circumstances, institutions, especially health institutions, act to reproduce or deepen social conditions related to vulnerability. It aims to discuss elements that shape the public health agenda and thus contribute towards a critical and dynamic reflection on public sector practices and actions. According to Ayres ${ }^{5}$, Muñoz-Sánchez and Bertolozzi ${ }^{6}$, this type of analysis provokes reflection to promote political, cultural, cognitive and technological changes which impact the epidemiological profile of violence and influence the support provided to social actors, in this case rural women, regarding their rights, which constitutes a challenge that must be pursued and overcome given the juncture between health and the country's development.

This study therefore aims to analyse health managers' perceptions of local public health agendas that address violence against rural women in municipalities in the southern part of the State Rio Grande do Sul.

\section{Methodology}

This study consists of an exploratory descriptive study utilising a qualitative approach. The study area comprises the geographical area covered by the Interdisciplinary Research Program (PROINTER, acronym in Portuguese), which is fruit of an interuniversity agreement between the Federal University of Rio Grande do Sul, the Federal University of Paraná, the University of Paris 7, the University of Paris 10, and the University of Bordeaux 2. The region covered by this program was the "southern part" of the State of Rio Grande do Sul, which has been experiencing a general slowdown in economic activity in comparison to other regions of the state, leading to visible regional disparities ${ }^{7}$.

A total of 13 municipal health managers responsible for planning actions directed at women's health and primary health care were selected based on the following inclusion criteria: participants must have been in the position at the time of data collection and have occupied the position for at least six months; participants accepted to participate in the study.

Data was collected utilising a semistructured interview based on an interview guide organised in two main themes: sociodemographic characteristics of the interviewee; open questions on 
the object of study. Interviews were previously scheduled with the health managers and conducted in their place of work between July and November 2010. To ensure anonymity and confidentiality of participants the narratives of the interviewees are presented using the abbreviation GES and number representing the order in which the managers were interviewed.

Thematic analysis was used consisting of pre-analysis, material exploration, processing and interpretation of results based on the recommendations of Minayo ${ }^{8}$. The organisation of empirical material and analyses were carried out using the software QRS NVivo version 7. The analysis sought to explore elements of programmatic vulnerability related to violence in the interviewees' narratives based on the following dimensions of programmatic vulnerability proposed by Mann et al. ${ }^{9}$ and Ayres et al. ${ }^{4}$ : expression of commitment, transformation of commitment into action, and planning and coordination.

This study was carried out in accordance with the norms of Resolution 196/96 ${ }^{10}$ which addresses research with human beings and obtained approval from the Research Ethics Committee at the School of Public Health of the Secretary of Health of the State of Rio Grande do Sul. Participants were informed of all aspects of the study and signed an informed consent form.

\section{Results and discussion}

\section{Expression of commitment: public health policies and the local level}

The effective decentralisation of health service proposed under Brazil's Unified Health System (SUS, acronym in Portuguese) presupposes that health managers possess the appropriate capacity to manage the public health services under their responsibility and the autonomy to organise the production of health actions. The study therefore sought to adopt a wide approach to the understanding and expression of commitment of group of managers, by initially analysing each interviewee's "reading" of public health policies and their knowledge of how to implement these policies to address violence against rural women.

A first reading of the narratives showed that public health policies consist of set of formal proposals or actions which guide the organisation and administration of health services. The analysis of the narratives detected the managers perceived that the state was responsible for pro- viding policies to the community, while managers were responsible for implementing and developing them at local level.

[...] public health policy is a set of actions that the state makes available to a community to solve given problems, given situations that are right for that population. [...] it is the municipal manager's task to implement and develop them at local level based on common interests $\left(\mathrm{GES}_{9}\right)$.

On the whole, the narratives show that managers perceive that health policies are developed based on community demands recognised as health issues, and that the responsibility to formulate them lies with national government, while the municipality's task (local level) is to implement them according to the specific needs of each particular situation.

In the first narrative, the manager mentions that the implementation of a given policy occurs based on common interests. In this respect, Arretche ${ }^{11}$ highlights that local autonomy in policy management creates institutional opportunities which allow governors to implement decisions based on their own preferences, which are not necessarily compatible with the public interest and well-being of the population. The institutional rules of a public policy provide the incentive for the behaviour of local governments.

It can therefore be inferred that, apart from submitting itself to a "political menu", the population is subjected to the manager's will and his or her perception of "needs". What is not implemented is attributed to the lack of interest and mobilisation of the population.

In this respect, and with good reason, some of the interviewees mentioned that health policies are synonymous with care protocols, as the following narrative shows:

If there weren't any public policies maybe there wouldn't be any 'patient care protocols'. I think these policies are important because care is all organised [...] creates the pregnant woman care program, the women's health program, prevention of breast cancer, cervical cancer $\left(\mathrm{GES}_{6}\right)$.

This perception demonstrates a narrow and fragmented understanding of policies, reducing them to a simple guide of how to conduct health care actions by following technical protocols, which result in repetitive protocol-driven actions, dismissing the social, cultural and economic situation of communities as unique determinants of health.

This approach and narrow understanding of the implementation of public policies is the main tone of the narrative. The managers' ignorance 
of public policies that address violence against women is also evident in the interviews:

Well, I don't have any knowledge of any health policy directed at this problem. Here in our municipality we have done practically nothing with this focus, not least because I didn't know of the existence of 'federal things' for this ( $\left.\mathrm{GES}_{11}\right)$.

[...] we don't have many cases of violence, and even less in rural areas. So we end up not pursuing policies that deal with this problem, given that we have numerous problems that demand political actions $\left(\mathrm{GES}_{1}\right)$.

It is apparent from these narratives that the violence phenomenon "doesn't exist" and is therefore not posed as a local problem that requires health actions. This apparent "inexistence" dispenses with the need for local health agendas. In other words, the way of thinking of health managers and those responsible for women's' health with respect to this problem does not translate into practices and actions and is therefore not conducive to putting proposals capable producing positive changes into practice, particularly in rural areas.

There are currently a number of public health policies which address violence against women. However, it was observed that in the study area only four of the thirteen health managers responsible for women's health mentioned having knowledge of such policies. This demonstrates the gap between national government proposals and what really finds its way to the local level. Specific public strategies to combat violence against women therefore exist, together with a number of challenges to their implementation at local level.

One of the main elements that contribute to this situation is the fact that these policies originate in the federal sphere, frequently without the participation or coordination with the other spheres and without public participation, therefore leading to a lack of shared responsibility between different levels of government. A second important element is that violence is not recognised as a health issue.

\section{Transforming commitment into action: focus on planning and strategies directed at violence against rural women}

It was observed that the disease-oriented approach to healthcare is predominant in local health services and that violence is not recognised as a broader health problem, particularly in the public health system. As a result, specific local health agendas directed at violence against as rural women do not exist. Evidence of isolated strategies linked to the Family Health Strategy (ESF, acronym in Portuguese) appears in some of the narratives:

[...] I don't see an effective administration or public policy directed at protecting women against violence, especially with regard to rural women [...] there are still no structured actions against this problem here in this municipality, and I believe that when they eventually come to exist, these policies have to come together with resources for us to implement them $\left(\mathrm{GES}_{11}\right)$.

[...] no, in effect, there are no structured actions at local level for rural women. Health ends up being fragmented in one way or another, despite us trying to contact and link all the teams. I'm not sure if they work with this in a specific manner in the CAPS (Psychosocial Care Centres), but I don't think so, I believe because violence still doesn't appear so much in health, but rather 'more in the area of (public) security' (GES ${ }_{13}$ ).

These narratives show that managers and those responsible for women's health consider violence to be a mental health and public security problem. Despite advances in terms of policies and norms, local health management proposals and care for women subjected to violence, little improvement has been seen in terms of the competences and responsibilities of health managers at local level.

The findings show a "transfer of responsibility" from the health sector to the public security sector with respect to the violence problem. This "transfer of responsibility" means that violence ends up being excluded from the health agenda, a fact which is reflected in the understanding that violence is part of "another sphere", which in turn legitimises the exclusion of this problem from rural public health services which are often sought by women as a "refuge".

The managers from the five municipalities with ESF coverage in at least part of the rural area mentioned that strategies to combat violence are limited to the actions promoted within the ESF, as the following extract shows:

It is expected that family health teams in rural areas are able to intervene and take action in cases of violence against women, and even sit down with these people, if they have a good relationship with the family, and discuss the problem with the couple $\left(\mathrm{GES}_{9}\right)$.

ESF forms part of a process to reorient health care delivery away from the current care model, through multidisciplinary patient-centred actions that focus on health promotion. According 
to Andrade and Fonseca ${ }^{12}$, ESF seeks to surpass the simple diagnosis of needs by listening to the patient, changing the power relations between service users and health professionals, and seeing women as full social beings which deserve dignity. In light of the above, ESF has the potential to propose and create local interventions to combat this phenomenon.

Therefore, given that ESF is characterized as a space for health promotion, violence against rural women falls under its responsibility, thus enabling the reflection and coordination of strategies to combat the problem with other health sector services and with formal and informal civil society organisations. However, the reach of these actions is limited in terms of coverage and quality.

In the first narrative above, the manager mentions that, given the complexity of the problem and divergent understandings, matrix support services were established to promote interventions based on an interdisciplinary and intersectoral approach. This perspective shows that the interviewee doesn't see ESF as having "superpowers" or being "a saviour", but rather as an important device in the combat of this problem where a care network is necessary to facilitate interdisciplinary and intradisciplinary dialogue in order to implement more wide-reaching therapeutic and care actions for rural women who are subjected to violence.

According to Conill ${ }^{13}$, ESF is neither a "Trojan horse" nor a "miracle solution" for health care system problems. Research and monitoring of the implementation of the ESF highlight a number of aspects of the programme which require modification. These aspects are not specific to the ESF, but are related to a wider range of issues that have historically marked the standard of health care delivery Brazil. Therefore, little can be expected with respect to non-programmatic interventions which are still not recognised as health issues, such as violence.

Current evidence points to a "discrete" change in interventions under the ESF in relation to the activities of traditional centres. However, a number of critical weakness are apparent, including access and difficulties related to the geographical distribution of health care, physical infrastructure of public health facilities, number of teams, and level of training and qualification of care workers in management and in the coordination of health service networks.

One of the municipalities has a division dedicated to women's health (Coordenadoria da Mulher) where incipient discussions are held with health workers and the community thus facilitating reflection and examination of this problem. According the following extract, this division seeks to propose working in networks, through uniting efforts of governmental and nongovernmental entities to act against gender inequality and discrimination against women:

[...] we have a partnership with the CRAS (Social Assistance Reference Centre), Health Secretary, Education Secretary and coordenadoria da mulher. So, the coordenadoria da mulher works with various sectors towards prevention, especially of violence, and encompasses rural women $\left(\mathrm{GES}_{5}\right)$.

We have a 'specialised reference centre', which provides care for victims of sexual abuse and all types of violence against women and against children and also receives women who are victims of violence from rural areas. But it still has a number of weaknesses $\left(\mathrm{GES}_{8}\right)$.

The role of the 'specialised reference centre' is to provide care for victims of violence and coordinate the institutions and government and nongovernment services that make up the woman protection network. This network facilitates access to these services for vulnerable women and those who have been subjected to whatever type of violence. However, this service prioritises demands that originate in urban areas in detriment to the specific characteristic of rural areas, despite the fact that the majority of the rural population live in rural areas.

Both of the abovementioned centres experience barriers to carrying out their work and activities are generally limited to receiving and providing counselling to victims of violence. These limitations are often due to the lack of local public policies to provide an effective response to women that find themselves in this situation, meaning that many cases are still resolved in very informal manner and on a case to case basis. Furthermore, weaknesses in the network and limited services reduce the possibility of a rapid response which would ensure the safety and preservation of the rights of rural women.

Therefore, initiatives that seek to provide care for victims of violence are generally isolated and are yet to be incorporated into a local care agenda directed at rural women who are subjected to violence. There is therefore a prevalence of isolated initiatives which are implemented without any understanding of the complexities of "dealing" with these situations and the unique nature of each case, and the consequences of this problem.

In the following extract from one of the interviews in the manager suggests that the man- 
agement actions directed at victims of violence in rural areas are preset and disorganised:

it's very automatic here in the secretary that everyone does their bit. Because you realise the violence that some woman has suffered and so you arrange mental health care, you refer them, depending on the type of violence, you make a natural referral, that is for us, and I have already preset some things [...] so the director of social assistance arrives, she, they don't have food, she arranges a food basket, the children's clothing is ragged, the psychologist talks to her, she has to have her tubes tied, that's a problem, the psychologist does an assessment, refers her to the social worker and we speak to the doctor $\left(\mathrm{GES}_{3}\right)$.

The fragmentation and compartmentalisation of the responses to this woman's health needs are rooted in the dominant concept of health care, which is more often than not taken for granted, which consists of a piecemeal and protocol-driven approach to the problem where each discipline (speciality) proposes its own part in the therapy, thus promoting isolated interventions, or in other words, the segmentation of health in which each part is the responsibility of a particular specialist and where each sector has its own sphere of operation and nobody assumes responsibility for the whole. Furthermore, this "preconceived" view of treatment demonstrates a traditional and normative form of management.

According to Cecilio $^{14}$, this view could be called "rationalised" and "technical", as real people and their anguish and suffering are seen as, using technocratic jargon, as a type of "agent" endowed with predictable behaviour, who should be compartmentalised based on this external rationality.

Based on this perspective, Mendes ${ }^{15}$ analysis of health care systems identified that they are dominated by fragmented systems directed towards the treatment of acute conditions and exacerbated chronic conditions. The author highlights that fragmented health care systems are organised according to a group of isolated healthcare facilities which do not communicate with each other and which are therefore incapable of providing continuous care.

It is also evident that professionals lack a basic understanding of the needs, wants and rights of these women and the importance of their active involvement in the therapy process. The system seems to simply offer a menu of referral options influenced by the biomedical model and limited due to the lack of technical capacity of the health services.
With respect to care networks, the narratives about local agendas show that health services maintain relations with social support services (CREAS, CRAS), the child protection service, EMATER (a state owned company which provides technical assistance in rural areas), and government agencies responsible for providing public security. It should be highlighted that these services do not comprise a care network as such because there is no interface between the various organisations, and thus end up providing only background "fragmented" support.

[...] there are some sectors that give support to victims of violence, however, the network ends up not working. At some point the network fails, because everyone doe his bit, but sometimes actions are duplicated because there is no common dialogue between these segments $\left(\mathrm{GES}_{13}\right)$.

Therefore, there is no communication between the service providers regardless of the type of provider. Each provider has their own distinct logic and services are rarely based upon guiding policies and the health needs of users and therefore actions are generally disjointed. These difficulties arise possibly due to the lack of an effective care network and of integrated policies between different spheres of government. The disarticulation of services made available as a result of the spontaneous efforts of certain individuals and sectors is "visible". In this sense, women, who are at the same time victims of violence and service users, construct personal trajectories of intersectoral collaboration.

Santos and Vieira ${ }^{16}$ sought to identify the organisations involved in the provision of care to women subjected to violence based on the current network of health agencies and social facilities. The results of this study corroborate the findings of the present investigation which suggest that, although sensitive to this issue, the health managers interviewed by this study do not think in terms of networks. The authors highlight that, in general, the coordination of services reflects a disjointed conception of care for these women. Different services may deal with a given type of problem depending on the type of problem but without coordinating interventions with other sectors. They reiterate Faleiros' ${ }^{17}$ words when they affirm that "a network is the coordination of actions between actors around [...] a political and social issue which is at the same time a profoundly complex and dialectic process". Therefore, the strategy of constructing care networks to address violence against women in rural areas is a challenge which goes beyond 
the protocol-driven approach to care, moving away from the individual actions of health professionals towards the service users, and creating opportunities to increase their participation in the implementation of solutions.

A number of interviewees mentioned general difficulties in constructing and consolidating actions directed at this group. The most cited difficulty centred on physical barriers in terms of geographical distance:

[...] it's the distance, transport, the distance. So it's difficult, because we have care itineraries which we sometimes don't manage to meet, like last week, on Monday it rained a lot. On Tuesday was medical care, but the nurses couldn't go because of the road, because when it rains the bridges flood and the team can't get there $\left(\mathrm{GES}_{5}\right)$.

The large size of the municipalities aggravates the situation and is used to "justify" isolated health actions in these areas. The remoteness of these rural communities means they are excluded from the constitutional right of universal and equal access to health services.

It can be seen that there are inequalities in access to health services or health services are inexistent. These inequalities are often justified by geographic distances in rural areas which, to a certain extent, exempts the public sector from its duty to provide health services to the population, seek alternatives and design proposals to ameliorate the situation.

Another obstacle to service provision mentioned by the interviewees was the lack of financial resources as the following extracts show:

[...] like I said, the main regulator are the financial sectors. The same goes for actions in rural areas, what we can do in rural areas, specifically directed at women $\left(\mathrm{GES}_{2}\right)$.

We have financial difficulties, personnel problems, we don't have enough personnel, and when there is a team sometimes there's no car. All the same, we carry out like collective actions, in schools, meetings with elderly groups and the rural community welcomes us really well, 'they answer our calls' $\left(\mathrm{GES}_{3}\right)$.

Lack of financial resources is cited as an impediment and is used as justification for not putting health actions into practice in rural areas. This difficulty appears to be the main focus of municipal service providers, because organisation and planning is based on the premise that "having resources" is essential, and therefore violence "does not exist" without resources - it is better that it remains invisible. Furthermore, it is necessary to include women's health in the pub- lic health agenda, in its broadest sense and in a way that goes beyond classical epidemiology. For this to happen, other indicators are needed which demonstrate gender inequality, for example, and have a daily repercussion on the life and health of rural women in public and private settings.

It is interesting to note that in the second extract above the health manager mentions that rural communities answer our calls, meaning that the population actively participates in proposed health actions. However, it could be asked whether the opposite is true. Do managers and health professionals answer the calls and meet the care demands of rural communities? It is clear that the service user has the responsibility to participate while the public health service is limited to isolated actions in rural areas based on a biomedical approach.

In summary, this study shows that local public health agendas do not encompass the reproductive health needs of rural women, and, to an even greater extent, fail to address the problem of violence experienced in these areas. Health actions and health services do not consider the social dynamics experienced by women living in rural areas.

\section{Final considerations}

The findings of this study show that violence is not a recognised issue from a health management perspective and thus local agendas that address violence against rural women do not exist. It is also evident that rural areas are included in public health agendas on a piecemeal basis and actions are designed and structured based on urban contexts. As a result, actions are detached from reality meaning that the demands and problems of rural areas remain unsolved.

The findings reveal that violence against rural women is considered an "uncomfortable novelty" by a health sector which is already uncomfortable with the rural setting, and also highlight the potential, limitations and weaknesses of local health management in addressing this problem. This is conducive to the reaffirmation of hegemonic concepts and health practices, especially in primary health care, where it would be expected to find proximity practices and innovative management. The repercussions are expressed in fragile comprehensive services for these women and programmatic vulnerability.

Health managers are therefore faced with the challenge of defining lines of action in accor- 
dance with the guidelines and principles of the SUS. Although a number of advances have been made in relation to these principles, comprehensiveness in the organisation and administration of health services has seen the least progress, or perhaps has been the "least visible" in the recent trajectory of the public health system in Brazil. Therefore, this aspect of comprehensiveness is one of the main issues that need to be tackled in order change health practices and services so as to recognise the rights and unique needs of rural women and acknowledge that they deserve to be at the centre of health service delivery.

The isolated actions developed in the municipalities investigated by this study show a lack of clarity, reflection and knowledge of health inequalities among health managers, reinforce inequalities and gender domination, and legitimise the power of the state, perpetuating equality and the gap between the legitimate demands of rural women and the provision of effective health care.

\section{Collaborators}

MC Costa participated in the theoretical conception and elaboration of this study and in drafting the final version of this article; MJM Lopes participated in the theoretical conception of this study, in the discussion of results and in drafting the final version of this article; JSF Soares participated in drafting the final version of this article. 


\section{References}

1. Minayo MCS. Violência e Saúde. Rio de Janeiro: Editora Fiocruz; 2006.

2. Kiss LB, Schraiber LB. Temas médico-sociais e a intervenção em saúde: a violência contra mulheres no discurso dos profissionais. Cien Saude Colet 2011; 16(3): 1943-1952.

3. Santos JVT. Conflitos agrários e violência no Brasil: agentes sociais, lutas pela terra e reforma agrária. In: Seminario Internacional, Pontificia Universidad Javeriana, Bogotá, Colombia[internet]. 2000. [acessado 2010 ago 1]. Disponível em: http://bibliotecavirtual.clacso.org. ar/ar/libros/rjave/paneles/tavares.pdf

4. Ayres JRCM, França Júnior I, Calazanas GJ, Saletti Filho HC. O conceito de vulnerabilidade e as práticas de saúde: novas perspectivas e desafios. In: Czeresnia D, Freitas CM, organizadores. Promoção da saúde: conceitos, reflexões, tendências. Rio de Janeiro: Fiocruz; 2003. p. 117-139.

5. Ayres JRCM. Sobre risco: para compreender a epidemiologia. $3^{a}$ ed. São Paulo: Hucitec; 2008.

6. Muñoz-Sánchez AI, Bertolozzi MR. Pode o conceito de vulnerabilidade apoiar a construção do conhecimento em Saúde Coletiva? Cien Saude Colet 2007; 12(2):319324.

7. Beck FL, Almeida J, Verdum R, Zanoni MM, Mielitz Neto CGA, Gerhardt TE, Raynaut C, Lopes MJ, Miguel LA, Souza GC. Construção de uma problemática interdisciplinar de pesquisa: trajetória e reflexões. In: Philippi Junior A, Silva Neto AJ, organizadores. Interdisciplinaridade em ciência, tecnologia e inovação. São Paulo: Manole; 2010. p.263-297.

8. Minayo MCS. O desafio do conhecimento: pesquisa qualitativa em saúde. $11^{\text {a }}$ ed. São Paulo, Rio de Janeiro: Hucitec; 2008.

9. Mann J, Tarantola DJM, Netter TW. A AIDS no mundo. Rio de Janeiro: Relume-Dumará, Abia, IMS, UERJ; 1993.
10. Brasil. Ministério da Saúde (MS). Conselho Nacional de Saúde. Resolução no 196 de 10 de outubro de 1996. Diretrizes e Normas Regulamentadoras de Pesquisas Envolvendo Seres Humanos. Diário Oficial da União 1996; 16 out.

11. Arretche M. Financiamento federal e gestão local de políticas sociais: o difícil equilíbrio entre regulação, responsabilidade e autonomia. Cien Saude Colet 2003; 8(2):331-345.

12. Andrade CJM, Fonseca RMGS. Considerações sobre violência doméstica, gênero e o trabalho das equipes de saúde da família. Rev Esc Enferm USP 2008; 42(3):591595.

13. Conill EM. Ensaio histórico-conceitual sobre a Atenção Primária à Saúde: desafios para a organização de serviços básicos e da Estratégia Saúde da Família em centros urbanos no Brasil. Cad Saude Publica 2008; 24(Supl. 1):S7-S27.

14. Cecilio LCO. Modelos tecno-assistenciais em saúde: da pirâmide ao círculo, uma possibilidade a ser explorada. Cad Saude Publica 1997; 13(3):469-478.

15. Mendes EV. As redes de atenção à saúde. Cien Saude Colet 2010; 15(5):2297-2305.

16. Santos MA, Vieira EM. Recursos sociais para apoio às mulheres em situação de violência em Ribeirão Preto, $\mathrm{SP}$, na perspectiva de informantes-chave. Interface (Botucatu) 2011; 15(36):93-108.

17. Faleiros VP. Estratégias em Serviço Social. São Paulo: Cortez; 1999.

Article submitted 23/04/2014

Approved 08/10/2014

Final version submitted 10/10/2014 
